\title{
Invention as a Link in Scientific and Economic Progress. ${ }^{1}$
}

\section{By Sir James B. Henderson.}

TNVENTION and discovepy are so closely allied that they are often confused. In our common speech the two terms arefrequently used as synonymous, and if one seeks an exact line of demarcation between them one finds it difficult, if not impossible, to distinguish one from the other in any but the most general terms. Both involve an increase in knowledge which may be great or slight, and may have an immediate effect or may take a lifetime or more to consolidate. Both involve scientific imagination. Fach may be only a happy idea, the inspiration of a moment or in some cases an accident, but the testing of the idea and its final enunciation as a physical truth or as a finished invention may occupy many years. Newton is reputed to have discovered the theory of gravitation on seeing an apple fall from a trec, but assuming that to have been the birth of the idca, we know that the completion of his discovery and tho proof of the universal law of gravitation took the best part of his lifetime and involved the invention of new branches of mathematics to complete the proofs.

The dividing line between discovery and invention is, in very general terms, the same as between theory and practice, between the abstract and the concrete. Discovery is essentially an increase in man's knowledge of Nature and its complexities, and is therefore intangible. It may be a discovery of a new principle, a new element, a new and hitherto unknown quality or eharacteristic of a known substance, and so on, but the discovery, per se, has no regard to any particular practical application of the new knowledge. Invention, on the other hand, has its sphere in the practical application of knowledge, and the knowledge used may be new or may be as old as the hills. It may be, and it is often the case, that invention involves other discoveries which may be complementary to the original discovery and form its completion, or may be entirely unrelated to it and form the nucleus of a new branch of study. It is possibly this fact, that the difficulties encountered in devcloping an invention often lead to new discoveries, which makes it so difficult to separate discovery from invention. I think, however, that this distinction in general terms is sound, that discovery is mental while invention is material, and while it is true that in the large majority of cases an invention is in its origin a mental conception, it is a conception of something material and practical, while a discovery begins and ends in the realm of the mind.

When one seeks to study the history of some of the great inventions, one begins to realise how exceedingly complex they are, despite their outward appearance of simplicity. As an example, take wireless telegraphy and telephony. No single person deserves the credit for its discovery

1 Jrom the presidential address delivered to Section $G$ (Engineering) of the Jritish Association at Leeds on Sept. 1. and invention. Maxwell, Hertz, Lodge, Crookes, Branly, Marconi, Jackson, Fleming, de Forest, Fessenden, and many others have contributed their share to its development, but the basis of wireless communication did not necessarily begin with Maxwell.

Hertz was the first to produce apparatus for transmitting and receiving wireless waves, and this apparatus was improved by Branly, Lodge, and many others, but for further progress finance was needed. 'The firsts steps to make a wireless tclegraphic installation worc taken in Italy by Marconi and in Great Britain by the Admiralty experiments carried out by Admiral Sir Henry Jackson, who was then a captain. In this kind of competition money counts for much, and in the development of an invention having a com. mercial as well as a service aspect, a commercial firm with good financial backing will always have a great advantage over a Government department with a strictly limited budget allowance for research. It says much, therefore, for the scientific direction of the Admiralty of that time, that the Admiralty is to-day numbered among the pioneers of this great invention.

Wireless has been taken as a typical illustration. To the man in the street it represents simply an invention, a single invention and an apparently simple one represented by a small wooden box with a knob to turn. But to the scientific historian who tries to decipher all that the little box represents in human thought and effort, it presents an appearance of amazing complexity in which the discoveries and inventions of some of the finest brains of two centuries are inextricably blended.

\section{Invention as a Historical Science.}

The science of invention is a curious blend of the exact sciences, like mathematics, physics, and chemistry, with a historical science. It is in many respects similar to the science of war, the war being against the complexity of Nature, man's ignorance of that complexity and the inefficicncy and insufficiency of the human intellect itself.

Yet if wo compare this contest with the wars of man with his fellow-man, what a difference we find. Napoleon said he learned the art of war from a study of the lives of the 'great captains,' but in the greater war with Nature, if we consult the books that have been written round the lives of its 'great captains,' we find only human documents in which the searcher after knowledge, to help him to carry the fight a little further, finds little help beyond an example of high courage. The technical difficulties are seldom recorded, and the new soarcher has generally to start afresh and reconnoitre his way across the old battleground of centuries. The fault sometimes lies with the chronicler, but too often with the lack of records which the "captain' might have left but

No. 3024, Vot. 120] 
failed to leave. In fact, here we have a startling lesson from the science of war, for is it not drummed into every budding soldier until it becomes second nature when he attains command, that one of his first duties in the field which must never be neglected is to maintain communication and pass on all information that may come his way, whether it be useful to him or not? The lesson has two sides. The soldier knows that he may become a casualty at any moment and the information which he gleans may be of vital importance to enable some one else to carry on in his stead ; also, that information which may appear unimportant to him may prove to be the key to the movements of the enemy elsewhere of which he is in entire ignorance.

Of the hundreds of inventions which have been abandoned as failures, or of possibly revolutionary inventions left incomplete simply from lack of capital or lack of courage, no record is available to those who come after and might carry them on to success. Has every inventor for all time to start from scratch? The same difficulties crop up time after time in the development of inventions, yet every new inventor has to tackle the difficulties de novo, and fortunes are wasted in the process.

Development of an invention is always costly, even when guided by all the experience obtainable from allied inventions; how much more costly it is when not so guided, the history of the failures would most surely show. In most inventions there comes a time when the inevitable question arises, "Shall we cut our loss or risk further expenditure?' If the decision is to cut the loss, the invention, which is possibly a sound one and of great value, is pronounced to be a failure, and the result may be the loss of an industry to the country or a delay in its introduction for many years. Science will prevail in the long run, but the cost of the trials both in time and money could probably be greatly curtailed if records of similar ventures in the past were available. Inventors would gain much if they could be trained in, and benefit by, the experience of their predecessors in the same field, while masters of industry, with records of that experience before them, would be better able to appreciate the difficulties of the inventor and to co-operate fully with him.

In every industry one finds that the experience gained in developing the inventions of the industry is often guarded as a most valuable secret. The result is that this knowledge is not recorded and often dies with the individuals who possess it. Future workers even in the same industry have to pass through the same or similar experience to regain the lost knowledge and the whole condition is economically unsound. The expense to the nation which it entails must be enormous. It retards progress, it adds greatly to the time and expense of developing other inventions, and it brings invention into disrepute because so many firms have lost money in trying to develop inventions which have had to be abandoned simply through inexperience.

\section{INVENTION AND INDUSTRY.}

The history of the twentieth century shows clearly that invention is the heart of industry, the root of new developments, and the source of improved methods of production which have led to cheaper costs and a wider scope in every industry. It has also been the cause of some of the greatest social upheavals and strife. Innumerable strikes have arisen from it, and if there is one lesson in political science more potent than another to be learned from the history of such movements, it is that science is always victorious in the end. Progress may be delayed or an industry may be lost to a country temporarily or permanently by such strife, but the steady advance of the world's progress through the science of invention is certain. One country may lose, but the world will gain in the end. It is only a question of time, and if the leaders of industry, both masters and men, would only recognise this fundamental truth, how much faster progress would be.

It must not be imagined, however, that every invention can or, from the commercial point of view, should be introduced into an industry the moment it is made. Quite apart from the time necessarily spent in developing and perfecting the invention, for which purpose many industries have now instituted research departments of incalculable value, it is sometimes found that the occasion is inappropriate or that the time is not ripe for the change involved. The introduction of a new invention or of a new design may involve many complicated questions of policy or finance, because the change may have to be accompanied by heavy sacrifice in other directions, possibly affecting other industries or the public at large. There may have to be heavy scrapping of spare parts, tools and plant. There may also be considerable loss to the customers of the industry through depreciation of the products of the industry already in use, for nothing depreciates a firm's production more rapidly than the introduction of a new and superior model.

Manufacturers have therefore, on some occasions, to collect and husband their inventions and improvements after testing their merits and keep them in reserve for a more opportune occasion. The opportunity may occur very suddenly. It may arise through a sudden whimsical change in fashion which no one can explain, or from some other cause which it has been impossible to anticipate, and if a manufacturer has no policy of improvement all worked out and ready to apply, he is faced with the awkward alternative of falling behind the times by making no change at all, or of risking his market by adopting some new model which he has not had sufficient time to test thoroughly. The former policy is almost always disastrous and the latter is often worse. Numerous illustrations of both these courses and their results could be cited from any industry. There inevitably comes to every industry a time when radical change is demanded, and the firm which is best prepared for the change reaps the reward of its foresight.

$$
\text { No. 3024, VoL. 120] }
$$


Industry when viewed in its international aspect determines the lives of nations. The nation which organises its industry most efficiently, which hampers it least and stimulates it most by legislation, or absence of legislation, and by its scientific foresight, is the nation which will prosper most. Since invention is the heart of industry, the inquirer naturally asks: Is this country doing its best to stimulate invention as a means to foster industry? Are the leaders of industry fully alive to the position which invention plays in industrial progress? Have our legislators ever paused to think that their functions are only called for because of the progrcss which has been made by scientific invention, and that without such progress thcy would be unnecessary; also that, in the past, legislation has done much to retard progress? A study of the fundamental scientific causes of progress would form a useful addition to the education of legislators.

Inyention as a Link Berwhen Exact Sciences.

It is sometimes stated that the physics of to-day becomes the engineering of to-morrow. This is a natural development, sinee the engineer is more concerned than the physicist with the practical application of physical discoveries. But the converse is frequently true, for many physical discoveries and inventions arise from difficulties encountered by the engineer. The science of practical hydrodynamics is a case in point. The mathematical science of hydrodynamies has been of little service to the engineer in the practical problems of the propulsion of ships, in the complex phenomena of vortex motion associated with the flow of water and steam through turbines, or in problems of aerodynamics, with the result that the engineer has had to develop an empirical science of hydrodynamies to supply his immediate needs. A huge mass of experimental results in screw propulsion, in aerodynamics and in hydraulics has thus been accumulated and is now awaiting some discovery or discoveries in mathematics or physics to correlate it all. If vortices could only be dealt with like potatoes or any other form of merchandise, each a complicated physical systern in itself but capable of being considered as a unit differing only in mass or in its energy contents, a forward step might be made. The LanchesterPrandtl theory of lift and drift of aeroplanes is a first step in a particular case of the general problem. Such a discovery, when made, will be bound to lead to further advances and improvements on the engineering side of the subject.

Most discoveries in physics arise from some experimental fact discovered more or less accidentally. The discovery of Rontgen rays was accidental, and the enormous strides which have been made in our knowledge of the atom by J. J. Thomson, Rutherford, Bragg, Bohr, and many other physicists during the last thirty years have resulted from Röntgen's discovery combined with another great discovery in pure thermodynamics, Planck's quantum thcory, which also arose from an accidental discovery made in the course of ex- periment. The Reichsanstalt in Berlin had published a family of curves representing the distribution of energy in the spectrum of a hot black body. Prof. Wien by trial and error obtained an equation to the family, and the form of this equation was suggestive. Planck, in trying to develop this equation from the laws of thermodynamics, found that he could only do so by assuming that energy is not indefinitely divisible, and he coined the term 'quantum' to represent the fundamental unit.

These two discoveries of Röntgen and Planck form the starting-point of that most important branch of modern physics which has increased our knowledge of the constitution of matter, a science which is just beginning to find its field of application in engineering practice, as in the thermionic valve and the modern power transformers on the same lines. From these and other applications great advanees are still to be expected.

In reviewing the discoveries in physics which have had most effect in developing new industries and thus calling forth new inventions, one is struck by the great results in this respect which have arisen from application of the second law of thermodynamics, first stated by Carnot in 1824 . Carnot described his ideal heat engine and showed that the efficiency of this engine is independent of the working substance used. Looking back upon the history of the science of thermodynamics of the last century, it is unfortunate that no one seems to have employed this statement of Carnot's as a general text, and developed it to find what information could be derived from it by using different working substances and mixtures in order to discover something about all the substances used. Had any one done so, progress might have been greatly accelerated.

James Thomson was the first to use this second law to detcrmine the lowering of the freezing-point of water due to pressure. His brother, Lord Kelvin, followed with the application to the change from liquid to vapour. Helmholtz used the voltaic cell as the working substance and determined the temperature coefficient of its electromotive force. Then followed at long intervals the applications to ehemical changes which have resulted in the modern science of thermodynamic chemistry with which the names of Helmholtz, Ostwald, Nernst, Van't Hoff, and Gibbs are so closely associated, and upon which the modern industry of chemical engineering is based.

It is a wonderful development to be able to prophesy that under certain conditions a certain chemical reaction will 1ake place, say, that the nitrogen and oxygen of the air will combine at certain temperatures and pressures in a definite proportion, and that the resultant oxide can be recovered and converted to nitrate and used as fertiliser to replace the imported article at an economic price. The applications of thermodynamic chemistry to explosives enable us to calculate the maximum prossure to be obtained by detonating an explosive, or to calculate the temperatures and pressures throughout the ex- 
plosion of cordite in a gun from the chemical constituents of the cordite. This possibility has gone far to raise internal ballistics from an empirical science to a branch of natural philosophy.

The advances which have taken place in the commercial development of chemical processes based upon this important new science of thermo- chemistry, although already considerable, are only in their infancy, but the men with the experience gained in practical development are very few; and as the experiments are generally very lengthy and expensive, the development of the industry is necessarily slow. The resultant saving to the country, however, will far outweigh the cost.

(To be continued.)

\section{Indian Agrbeciftural Practice and Research.}

$\mathrm{D}$ URING the pasthentu of British rule, many attemptschare Been made to improve Indian agriculture ; but wave after wave of effort has broken, with little result, on the firm foundations of the indigenous practice of the country. Until within quite recent years, only in the fundamental matters of irrigation and reduction of famine has any notable advance been made. It is well, then, to look back and try to form a picture of the nature and origin of this indigenous agricultural practice.

When we do so, we are at once struck by the commanding position of the industry in former times, and the enthusiasm with which it was carried on. It is generally agreed that the Aryans, an agricultural people, entered the north-western part of India some 4000 years ago; and the view is also held, although more conjecturally, that the Dravidians, also noted agriculturists, had then already intrenched themselves in the south. Of the latter we have little knowledge. But there is detailed evidence in the ancient writings of the delight with which the Aryans regarded cultivation-witness the following extracts from a pastoral hymn on ploughing in the Rig Veda (period 2000 to 1400 B.c.) : " Let the god of rains moisten the earth with sweet rains . . . may the crops be sweet to us . . . turn the sod merrily, let the oxen work merrily, let the plough move on merrily, fasten the yoke merrily, apply the goad merrily." 1 Allowing for a certain poetic exaltation, this was a bright beginning; and was undoubtedly followed by a great development of agricultural knowledge and practice in north India. There appears to have been steady progress at any rate until the early part of the Buddhist period (500 B.C. to A.D. 500); and western knowledge of Indian agriculture dates from this period, in that it was carefully studied by the Greeks, shortly after Alexander the Great entered the country in 326 B.c.

In ancient India, soils were classified according to colour, taste, productivity, and suitability to particular crops; alkalinity was known and feared; irrigation was widely spread, by dams, tanks, and wells; methods of dry farming were practised ; deep ploughing was universal ; manuring with animal residues and with oil cakes was practised, and green manuring was known and valued; paddy was sown in nurseries and transplanted into puddled fields; most of the crops now grown were cultivated; the seasons and rains were well understood and allowed for, and agricultural practice seems to have reached a high

\& “Ancient India," R. C. Dutt, 1896.

No. 3024 , VoL. 120] level. ${ }^{2}$ But after the peak was reached, there would appear to have set in a steady decline both in the enthusiasm for agriculture and in the importance attached to it. Most of the details have, however, been handed down by example and oral tradition to the present day. But an Indian writer, after discussing these ancient glories and the progress being made elsewhere, allows himself to describe the Indian cultivator as " an ignorant, custom-bound creature, forced to content himself with his lot." Naturally, the inquiring western student will not altogether agree with this ; rather is he struck by the wealth of detail, the rare economy, and the surprising adaptation to environment; and he soon discovers in that environment the main reason why Indian agricultural practice appears to be a mass of contradictions, when first viewed by those trained in western scientific methods.

Putting it briefly, the work of the Indian cultivator is often excellent, considering the limits of his conditions and resources. The first business of any one desiring to improve matters must be a study of this environment. The important benefit conferred by British rule in the development of irrigation has been already referred to ; the next great advance was made when, in the early years of the present century, the Government at last recognised the necessity of founding an adequate agricultural department and allocating funds for its permanence. This was done on a generous scale by Lord Curzon, and during the past quarter of a century this department has been expanding and ' digging itself in' ; in place of some half-dozen agricultural officers, nearly 200 superior posts have been created, and the number is daily increasing.

Defining research as the detailed study of any subject by a scientifically trained mind, the first difficulty of these officers was to bring their training into alignment with Indian conditions. Any attempt at betterment was of necessity dependent on a knowledge of the local climate, soils, stock, implements, crops, and the resources of the people. Amelioration or alteration was obviously needed, but a series of interlocking factors made this very difficult. Irrigation and dry farming had been practised from ancient times, but are always susceptible of improvement. There is plenty of good soil in India, but much of it has, by continual cropping without due return, reached the verge of 'permanent infertility.' There is a marked deficiency of pasture land, and what there is, is often very inferior ; the cattle, therefore, although

G. Jogi Raju, Journal Madras Agricultural Students' Union, 8, $2-4,1920$. 